\section{Response to Evans et al.}

We appreciate the comments by Evans et al. on our paper entitled "MSH6 and PMS2 germ-line pathogenic variants implicated in Lynch syndrome are associated with breast cancer." We agree with many of the limitations outlined in their letter to the editor, and we have previously discussed these limitations in the discussion of our original article as well as in our response to ten Broeke et al. ${ }^{1,2}$ We will therefore limit our response to the points Evans et al. ${ }^{3}$ raise that we have not previously addressed.

In our paper, we reported standardized incidence ratios (SIRs), not odds ratios (ORs) as stated by Evans et al. The main difference between the two is whether an internal or external reference population is used. As we described in our paper, we calculated SIRs based on population-based incidence rates from SEER and caution that the calculated SIRs may be biased given that our study population was predominantly comprised of women with a personal or family history of breast cancer. Nevertheless, the SIRs published for our cohort are very similar to the ORs reported by other similar studies. For example, our findings were consistent with those of Couch et al., ${ }^{4}$ which Evans et al. consider "a more appropriate use of panel data" with an OR $=1.93$ (95\% confidence interval [CI], 1.16-3.27) for MSH6, compared with our SIR of 2.11 (95\% CI, 1.56-2.86). We acknowledge that PMS2 poses greater analytic challenges because of the highly homologous pseudogene that may have led to genotyping inaccuracies in some studies and lower penetrance. The data supporting the association of breast cancer with PMS2 is not as consistent as the data supporting association of breast cancer with MSH6. We previously addressed the comparison of our results to previous studies of $P M S 2$ available at the time of publication in our response to ten Broeke et al. ${ }^{2,5}$

As already discussed in our original paper, we acknowledge that our estimates of cumulative incidence may be overestimated given our retrospective study design, and we fully agree that estimates of cumulative incidence need to be confirmed by prospective validation, ideally using populationbased methods for mutation estimates.

Evans et al. postulate that we "ignore(d) most of the negative evidence available"; however, both publications cited in support of this statement were published after our manuscript was submitted. ${ }^{6,7}$ Had either paper with evidence suggesting lack of association been available prior to submission of our manuscript, we would have included the published data within the discussion of our manuscript. The Møller et al. ${ }^{6}$ publication using data from the Prospective Lynch Syndrome Database, while new, still suffers from the limitations discussed in our response to ten Broeke et al. ${ }^{2}$ In brief, this prospective cohort is also subject to ascertainment bias due to increased colorectal cancer risk and established clinical criteria for Lynch syndrome ${ }^{8}$ and is not likely to represent true population-based ascertainment of all individuals with a MSH6 and PMS2 pathogenic variant. This ascertainment method has likely resulted in a lower than expected number of MSH6 and PMS2 pathogenic variants as evidenced by comparison with the estimated general population frequencies reported by Win et al. ${ }^{6,9}$ Additionally, the Prospective Lynch Syndrome Database (www.lscarisk.com) clearly states that due to the small number of $P M S 2$ carriers, risk estimates should be interpreted with caution and are insufficient for reliable conclusions. With regard to the ten Broeke et al. (2018) publication, the lack of replication of their previously published elevated PMS2 SIR, 2.92 (95\% CI, 2.17-3.92) for breast cancer was published after acceptance of our manuscript and suggests the need for additional studies of PMS2 in particular. ${ }^{5,7}$

Rarely is any one study completely free of ascertainment bias, not even prospective studies. We have acknowledged that our referral population is enriched for all types of cancer, so if the increased risk of breast cancer were only due to the relatively high frequency of these two genes, then we would have expected to see an increased risk for other cancers, not just breast, as well. We attempted to account for the ascertainment bias in a number of ways, and acknowledge it in the limitations of our study. ${ }^{1}$ Furthermore, we specifically observed the increased breast cancer risk only with MSH6 and PMS2 and not with MLH1 or MSH2 although all patients were ascertained by the same method.

As we discussed in our paper and response to ten Broeke et al., our data showed a modest but statistically significant increased risk for breast cancer for both MSH6 and PMS2 with SIRs of 2.11 (95\% CI, 1.56-2.86) and 2.92 (95\% CI, 2.17-3.92), respectively. We strongly agree that the evidence needed to change clinical management is not derived from any single study, rather through robust replication, ideally with prospective unselected individuals that may be available through unselected, population-based biobanks that are linked to cancer registries. We are gratified that our paper has stimulated discussion and debate and hope other groups continue to investigate the association of breast cancer with some molecular subtypes of Lynch syndrome.

\section{DISCLOSURE}

M.E.R. is an employee of GeneDx/BioReference Laboratories, Inc./ Opko Health, and has a salary as the only disclosure. W.K.C. is a former employee of BioReference Laboratories. B.D.S. has multiple disclosures, which include stock options and employment 
with GeneDx/BioReference Laboratories/Opko Health. The other authors declare no conflicts of interest.

Maegan E. Roberts, MS ${ }^{1}{ }^{1}$, Nur Zeinomar, PhD, $M P H^{2}$, Benjamin D. Solomon, $M D^{1}$, Mary Beth Terry, $P h D^{2}$ and Wendy K. Chung, $M D, P h D^{3}$

${ }^{1}$ GeneDx, Gaithersburg, MD, USA; ${ }^{2}$ Department of Epidemiology, Columbia University, New York, NY, USA; ${ }^{3}$ Department of Pediatrics and Medicine, Columbia University, New York, NY, USA. Correspondence: Maegan E. Roberts (mroberts@genedx.com)

\section{REFERENCES}

1. Roberts ME, Jackson SA, Susswein LR, et al. MSH6 and PMS2 germ-line pathogenic variants implicated in Lynch syndrome are associated with breast cancer. Genet Med. 2018;20:1167-1174.

2. Roberts ME, Zeinomar N, Solomon BD, Terry MB, Chung WK. Response to ten Broeke et al. Genet Med. 2018 May 24; doi:10.1038/s41436-0180031-7 [Epub ahead of print].

3. Evans DG, Woodward ER, Lalloo F, et al. Are women with pathogenic variants in PMS2 and MSH6 really at high lifetime risk of breast cancer? Genet Med. 2018 December 14; https://doi.org/10.1038/s41436-0180401-1. [Epub ahead of print].
4. Couch FJ, Shimelis $\mathrm{H}$, $\mathrm{Hu} \mathrm{C}$, et al. Associations between cancer predisposition testing panel genes and breast cancer. JAMA Oncol. 2017;3:1190-1196.

5. ten Broeke SW, Brohet RM, Tops CM, et al. Lynch syndrome caused by germline PMS2 mutations: delineating the cancer risk. J Clin Oncol. 2015;33:319-325.

6. Møller P, Seppälä TT, Bernstein I, et al. Cancer risk and survival in path_MMR carriers by gene and gender up to 75 years of age: a report from the Prospective Lynch Syndrome Database. Gut. 2018;67: $1306-1316$.

7. ten Broeke SW, van der Klift HM, Tops CMJ, et al. Cancer risks for PMS2associated Lynch syndrome. J Clin Oncol. 2018:36:2961-2968.

8. Møller P, Seppälä T, Bernstein I, et al. Cancer incidence and survival in Lynch syndrome patients receiving colonoscopic and gynaecological surveillance: first report from the prospective Lynch syndrome database. Gut. 2017:66:464-472.

9. Win AK, Jenkins MA, Dowty JG, et al. Prevalence and penetrance of major genes and polygenes for colorectal cancer. Cancer Epidemiol Biomarkers Prev. 2017:26:404-412.

Advance online publication 19 December 2018. doi:10.1038/s41436-018-0400-2 